showed $B$. diphtherice in almost pure culture. The organisms were of the barred type, very large, with marked tendency to club formation. Cultures from this membrane on Loeffler serum at 35 degrees C., examined after seven hours, gave the solid type, and after twenty-four. hours the usual granular organisms. The direct smears from the infected finger showed small organisms of the solid type. Cultures from the infected finger at 35 degrees C. gave the solid type after seven hours, and after twenty-four hours the usual granular organisms, exactly as did the original membrane. 'This illustrated beautifully the possibility of morphologic variations in the same strain of organisms when infecting individuals under different conditions.

\section{INSTRUMENT FOR APPROXIMATION OF THF PALATINE PROCESSES IN CASES OH CONGENITAL CLEFT PALATE}

\author{
L. J. HAMMOND, M.D. \\ Surgeon, Methodist Episcopal Hospital \\ PIIILADELPHIA
}

The method advocated by Brophy for bringing the palatine processes in apposition as a preliminary to operative procedure for uniting the soft parts, and so successfully employed by him, has not in my hands been so satisfactory. Even when successful it is so at the expense of a great amount of mutilation of the parts and suffering of the individual. The one other method that has been more generally employed with instances of satisfactory results is that of having the mother encourage the inward growth of the cheeks and, consequently, the palatine processes by firmly compressing the cheeks on either side with the two hands at the same time. This method, of course, can only be successfully employed before ossification has caused fixation.

My repeated failures, therefore, with most of the devices heretofore employed in retaining the palatine processes in position have incited me to devise the comparatively simple instrument shown in the illustration. It is most efficient in all cases in which there is enough of the palatine processes present to be brought together. This can be done at once when the subject is under 5 or 6 months of age. After this period it can be officiently done by continuously increasing pressure, which should be continued over a period of four or six wecks.

The instrument consists of two lateral plates, semjoval, so as to conform to the shape of the lateral haives of the superior maxillary bone, fastened together in front by a hinge in order to prevent any play of the lateral half while being introduced. They are brought together by a central right and left screw which is so arranged as to bring together or separate the two lateral plates simultaneously. Sufficient force can be employed by this screw to bring together the palatine processes in any case in which ossification is not a factor; and in cases in which ossification has advanced so far as to prevent immediate approximation, an increased pressure kept up by tightening on the screw will in a short while secure the same result. The fingers alone may be used to tighten the screw, or when the instrument is in position the key which accompanies it can be best employed for this purpose. The two teeth, which are set posteriorly along the inner and upper edge of each lateral plate, are of two-fold value: first, in holding the plates in position by their fixedness in the bony alveolus, and, second, in lessening the injury to the spongy alveolar tissue throughout its entire surface over which the lateral plates are applied. They therefore lessen the general pressure of the entire plate; consequently, what injury the spongy alveolar processes suffer will be mostly at the points where these teeth are fastened.

There is no reason to believe there is any great amount of suffering caused by its use, as its employment, beginning in children as young as 2 days, has not lessened either their general nutrition or development.

1222 Spruce Street.

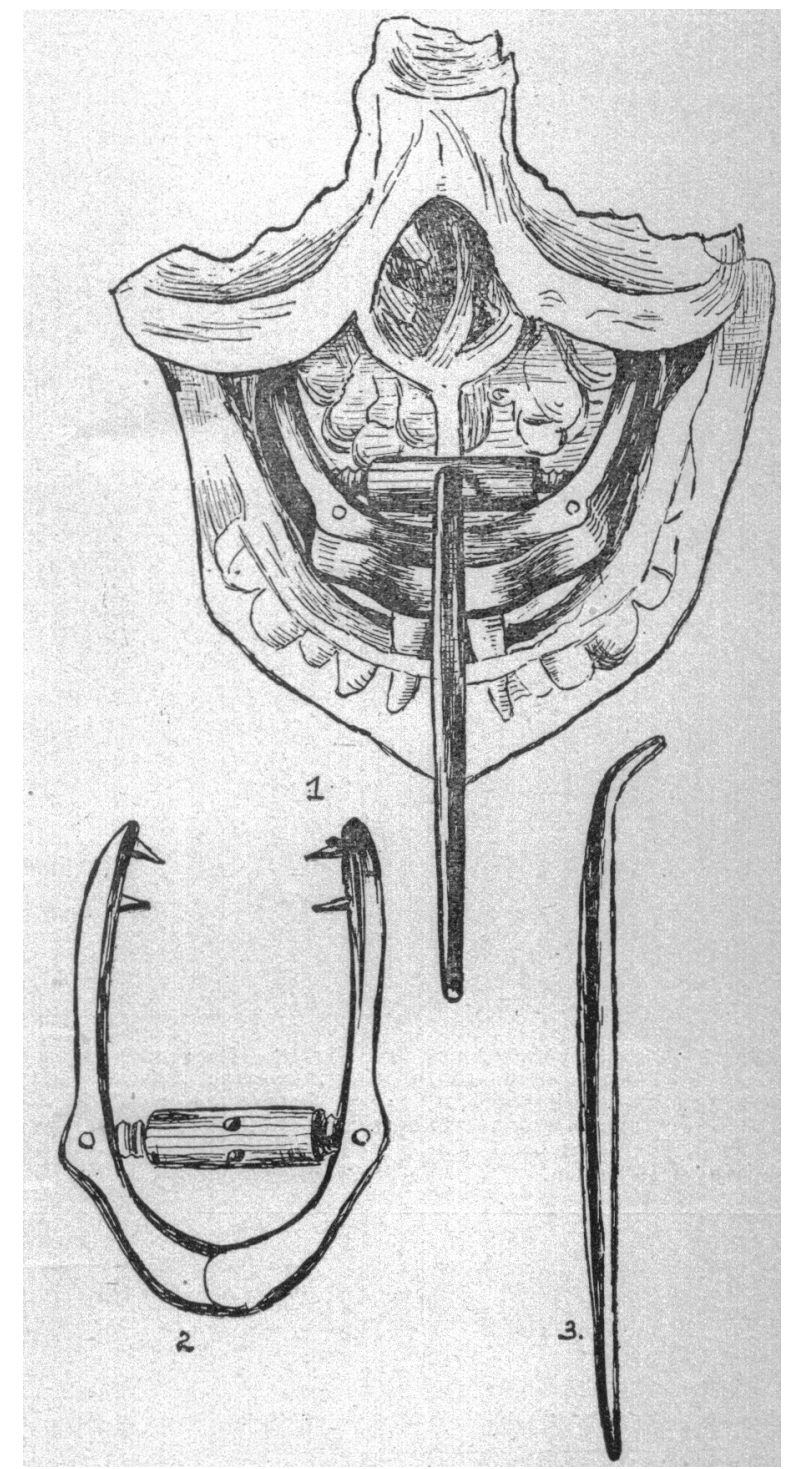

Fig. 1.-Instrument for approximation of the palatine processes in cleft palate in position. Fig. 2.-Instrument partly closed. Fig. 3.-Key.

Specific-Gravity Test for Identification of Criminals.-Debenedetti suggests that important information might be obtained from the individual displacement of water, the special specific gravity, as a means of identifying criminals. He publishes an illustrated communieation on the subject in the Semana Medica, of Buenos Aires, Dec. 31, 1908, p. 1781. Even if the specific gravity of the arm or leg or head were tested alone, possibly sufficient information might be obtained. The water must be always at the same temperature, for which he suggests $37 \mathrm{C}$. $(98 \mathrm{~F}$.), adding that a little salt in the water brings the specific gravity to that of distilled water at $4 \mathrm{C}$. He calls the method "hydrostatic anthropometry;" it is not necessary for ordinary criminals, he remarks, but cases may arise in which further means of identification may be useful. 